\title{
IMPACT OF COMPRESSION RATIO ON SUBSTATION GROUNDING GRID RESISTANCE IN LAYERED SOIL
}

\author{
Unde M. G' ${ }^{1}$ Kushare B. $\mathbf{E}^{2}$ \\ ${ }^{1}$ Prof, Electrical Engineering Department, P. D. V. V. P. College of Engineering, Ahmednagar, M.S., India \\ ${ }^{2}$ Prof. (Dr), Electrical Engineering Department, K. K. W. I. E. E \& Research, Nashik, M.S., India
}

\begin{abstract}
This paper presents impact of grid compression ratio on substation grounding resistance. The minimization of substation grounding resistance is one of the very important criterions in design of substation grounding grid. The decrease in grid resistance reduces the ground potential rise and hence the transfer potential and to a certain extent the safety criterion touch voltage. The term compression ratio is related to unequally spaced grid. We have analyzed the grounding grid for various values of compression ratios for uniform soil model with and without vertical rods. Further the impact of compression ratio on grid resistance is analyzed for various values of soil resistivity reflection factors and top layer height in case of two layer soil model. The simulation has also been carried out for multilayer soil models using Autogrid-pro grounding software. The study results reveals that every ground grid has optimal compression ratio which makes the grid resistance minimum as compared to equally spaced grid for the same area, soil model and number of conductors. Use of ground rods, increases the compression ratio, makes the grid more uniform and decreases the grid resistance.
\end{abstract}

Keywords: compression ratio, optimal compression ratio, equally spaced grid, unequally spaced grid, ground rods, soil model.

\section{INTRODUCTION}

A good grounding system is the fundamental insurance towards safety of the substation. The minimization of grid resistance is one of the important criterion for design of any substation grid in order to reduce the ground potential rise (GPR) and hence, the transfer potential [1]. The ground potential rise is the product of grid current $(\mathrm{Ig})$ and ground resistance $(\mathrm{Rg})$. Usually, grounding grid is made up of several horizontal equispaced parallel grid conductors interconnected to each other and buried in the earth at a certain depth. Sometimes vertical rods are provided at the corners and periphery of the grid to reduce the grid resistance [2]. In a homogenous soil, as a first approximation minimum value of grounding resistance of a horizontal grid is given by,

$$
R_{g}=\frac{\rho}{4} \sqrt{\frac{\pi}{A}}=\frac{\rho}{4 . r}
$$

Where,

$\mathrm{R}_{\mathrm{g}}=$ substation grounding resistance in $\Omega$

$\rho=$ soil resistivity in $\Omega-\mathrm{m}$

$\mathrm{A}=$ area of grounding grid in $\mathrm{m}^{2}$

$r=$ equivalent radius of grounding grid, assuming that grid

is made up of a circular metallic plate placed on the surface of earth.
The researchers Laurent [3] improved the formula in equation (1) by adding the length of grounding conductors.

$$
R_{g}=\rho\left[\frac{1}{4 \cdot r}+\frac{1}{L_{t}}\right]
$$

Where,

$\mathrm{L}_{\mathrm{t}}=$ total length of horizontal conductors placed on the earth surface.

Sverak [4] proposed the formula by considering the depth of grounding grid.

$$
R_{g}=\rho\left[\frac{1}{L_{T}}+\frac{1}{\sqrt{20 A}}\left[1+\frac{1}{1+h \sqrt{20 / A}}\right]\right]
$$

Where,

$\mathrm{h}$ is the depth at which grid is buried.

Area of grounding grid is the single most key factor on which resistance of ground grid depends. Thus, when area of grounding grid and soil model is specified, the effect of the grid conductor spacing, grid conductor diameter, buried depths, soil resistivity, compression ratio (CR) has negligible effect on reduction in grid resistance. However, as a researcher, we have focused on the reduction in grid resistance due to unequally spaced grid conductors at several compression ratios. 
Many researchers are working on unequally spaced grounding grid. The fault current dispersion in equally spaced grid is not uniform due to shielding effect which makes non uniform surface potential distribution and hence safety criterion touch voltage $[5,6]$. The touch voltage is higher at peripheral meshes and becomes maximum at the center of the four corner meshes of the grid. The magnitude of touch voltage decreases towards the meshes in central region of grid. Thus, grid corner mesh to centre mesh voltage ratios becomes very high [7, 8, 9 ]. G J Sverak [10] proposed the system of unequal spacing of grid first time but it does not explain the procedure for calculating grid spacing of grid conductors. Procedure for unequally spaced grid analysis for uniform soil is published in [11]. However, no information is available for two layer soil model.

The objective of this study is to analyze the impact of CR on grid resistance to provide efficient, economic and safety grounding design. The rest of the paper is organized as follows. The principle of unequal spacing is explained in section 2, followed by impact of CR on grid resistance for uniform soil model in 3 . Section 4 presents effect of CR on two layer soil model whereas as impact of CR in multilayer soil model is discussed in section 5. At the end concluding remarks are depicted in section 6.

\section{PRINCIPLE OF UNEQUAL SPACING}

Equally spaced grid has equal conductor spacing throughout the grounding grid area whereas, in unequally spaced grid, grid conductors are densely populated at the periphery of the grid and sparse at the centre region of the grid. In unequally but exponentially spaced grid, number of horizontal grid conductors and area of substation grid remains same as that of the equally spaced grid. This type of grid arrangement makes surface potential distribution more uniform and hence, reduces safety touch voltage, step voltage and grid resistance. The term compression ratio is related to unequally spaced grounding grid.

\subsection{Compression Ratio}

It is the ratio of mesh spacing between successive pair of meshes from perimeter to center of the grid either in $\mathrm{X}$ - or $\mathrm{Y}$ - direction of the grid. Compression ratio for exponentially spaced grid conductor remains same throughout the grid. The spacing of $n^{\text {th }}$ conductor counting from center mesh $(\mathrm{CM})$, either in $\mathrm{X}$ - or $\mathrm{Y}$ - direction is given by

$$
d_{n}=d_{\max } \cdot C R^{n}
$$

Where,

$\mathrm{CR}$ is compression ratio $\leq 1$

$\mathrm{d}_{\max }$ maximum spacing of centre mesh

Compression ratio is 1 for equally or uniformly spaced grid.

For unequally spaced grid, compression ratio is always less than 1. Higher the compression ratio more uniform will be the grounding grid and lesser the compression ratio more conductors will be crowded at the periphery of the grid and sparse at the central portion of the grid. If the grid is made up of $\mathrm{N}$ number of horizontal conductors [conductors in $\mathrm{X}$ -
$\mathrm{Y}$ directions] and $\mathrm{L}$ is the length of the grid conductor either in $\mathrm{X}$ - or $\mathrm{Y}$-direction, then centre mesh spacing $\mathrm{d}_{\max }$ is given by [12]

$$
\begin{gathered}
d_{\text {max }}=\frac{L(1-C R)}{1+C R-2 . C R^{N / 2}} \quad \text { when } N \text { is even } \\
d_{\text {max }}=\frac{L(1-C R)}{2\left(1-C R^{N-1 / 2}\right)} \quad \text { when } N \text { is odd }
\end{gathered}
$$

Where,

$\mathrm{N}=\mathrm{N}_{1}$ number of conductors parallel to X-direction $\mathrm{N}=\mathrm{N}_{2}$ number of conductors parallel to $\mathrm{Y}$-direction $\mathrm{L}=\mathrm{L}_{1} \quad$ length of conductor along the length of the grid $\mathrm{L}=\mathrm{L}_{2} \quad$ length of conductor along the width of the grid $\mathrm{L}=\mathrm{L}_{1}=\mathrm{L}_{2}$ for square grid.

\subsection{Grid Shapes}

Fig 1. (a), (b) and (c) depicts the equally and unequally spaced grids. For any grid if the number of horizontal grid conductors $\mathrm{N}$ is even; number of meshes will be odd in both $\mathrm{X}$ and $\mathrm{Y}$ - directions and if grid conductors are odd, the number of meshes will be even number. The unequally but exponentially spaced square grid shown in fig. 1 (b) has even number of conductors in both $\mathrm{X}$ and $\mathrm{Y}$ direction and therefore has only one center mesh and all other meshes are symmetrical in both the directions. Fig 1(c) shows the exponentially spaced rectangular grid with odd number of conductors in $\mathrm{X}$ and $\mathrm{Y}$ directions. In such cases there are four $(2 \times 2)$ equally spaced center meshes and the grid is symmetrical in either directions. We require to calculate conductor spacing only on one side of center mesh along the length and width of the grid and other sides are obvious symmetrical. If there are $\mathrm{N}$ conductors in $\mathrm{X}$ - or $\mathrm{Y}$ directions, then number of conductor spacing need to calculate counting from center mesh are,

$$
\begin{array}{ll}
\mathrm{n}=\frac{N-3}{2} & \text { when } \mathrm{N} \text { is odd } \\
\mathrm{n}=\frac{N-2}{2} & \text { when } \mathrm{N} \text { is even. }
\end{array}
$$

\section{UNIFORM SOIL MODEL}

Uniform / homogenous soil model is rarely exists in the geographical area of substation to a considerable depth. In practice, there are many layers, with different resistivities. Soil resistivity variations are found vertically as well as laterally. However, it is said to be homogeneous soil if the soil resistivity variations are $₫ 30 \%$, of the average value [13]. The average value of soil resistivity is given by

$$
\rho_{a v}=\sum_{i=1}^{i=n} \rho_{a i} / n
$$

Where,

$\rho_{a i}$ are the measured apparent soil resistivity field data obtained at different probe spacing's.

$\mathrm{i}$ is from 1 to $\mathrm{n}$

$\mathrm{n}$ is the total number of readings taken. 
The grounding grid selected for analysis is square grid with dimensions 70 × $70 \mathrm{~m}$. It is taken from IEEE Std 80-2000 appendix B. with 11 uniformly spaced conductors each in $\mathrm{X}$ - Y-directions. All the conductors having diameter $0.010 \mathrm{~m}$

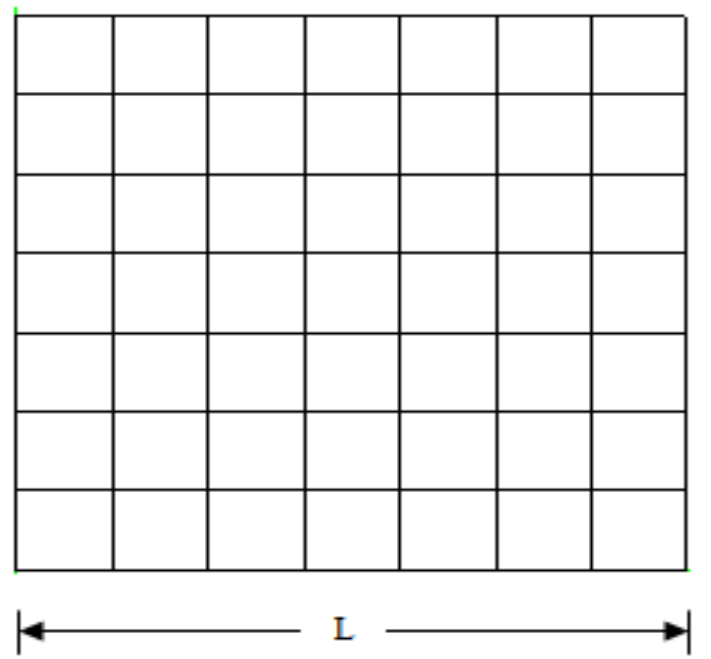

(a) Equally spaced square grid $\mathrm{CR}=1$

\begin{tabular}{|c|c|c|c|c|c|c|}
\hline & & & 3 & & & \\
\hline & & & 2 & & & \\
\hline & & & 1 & & & \\
\hline \multirow[t]{4}{*}{3} & 2 & 1 & $\mathrm{CM}$ & 1 & 2 & 3 \\
\hline & & & 1 & & & \\
\hline & & & 2 & & & \\
\hline & & & 3 & & & \\
\hline
\end{tabular}

(b) Unequally spaced square grid $\mathrm{CR}=0.8$

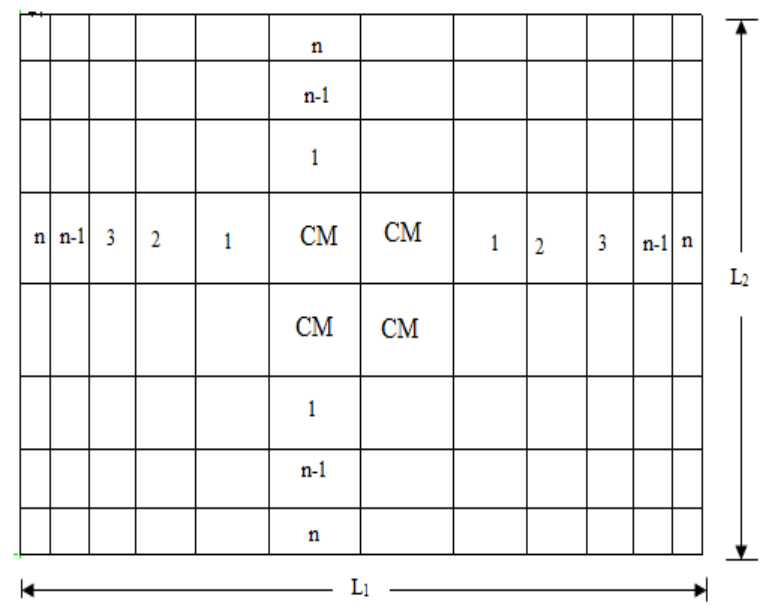

(c) Unequally spaced rectangular grid $\mathrm{CR}=0.8$

Fig -1: (a), (b) and (c) grid shapes with CR are buried at a depth of $0.5 \mathrm{~m}$. The soil resistivity $\rho=400$ $\Omega-\mathrm{m}$. The change in grid resistance with CR is tabulated in table 1 .

Table -1: Effect of CR on grid resistance Rg,

\begin{tabular}{|l|l|l|}
\hline \multirow{2}{*}{$\mathrm{CR}$} & \multicolumn{2}{|l|}{ Grid resistance $\mathrm{R}_{\mathrm{g}}(\Omega)$} \\
\cline { 2 - 3 } & No rods & With $3 \mathrm{~m} \mathrm{rod}$ \\
\hline 1 & 2.6222 & 2.6043 \\
\hline 0.95 & 2.6166 & 2.5994 \\
\hline 0.90 & 2.6111 & 2.5946 \\
\hline 0.85 & 2.6102 & 2.5943 \\
\hline 0.80 & 2.6058 & 2.5906 \\
\hline 0.75 & 2.6021 & 2.5875 \\
\hline 0.70 & 2.6035 & 2.5895 \\
\hline 0.65 & 2.6019 & 2.5885 \\
\hline 0.60 & 2.6020 & 2.5890 \\
\hline 0.55 & 2.6058 & 2.5933 \\
\hline 0.50 & 2.6082 & 2.5961 \\
\hline 0.45 & 2.6165 & 2.6046 \\
\hline
\end{tabular}

Fig. 2 depicts the impact of compression ratio on grid resistance in uniform soil model with and without ground rods. Both the curves have $U$ shape. Once the area of grounding grid and soil model are specified, every grounding grid has one compression ratio which makes grid resistance, touch voltage and step voltage minimum is known as optimal compression ratio ( OCR).With no rods the grid resistance becomes minimum at $\mathrm{OCR}=0.65$. The grid resistance changes from $2.6222 \Omega$ to $2.6019 \Omega$ which is $0.774 \%$ only due to exponentially spaced grid. By the use of $3 \mathrm{~m}$ long ground rods at the four corners of the grid, resistance becomes $2.5875 \Omega$ at OCR 0.75 making the grid more uniform.

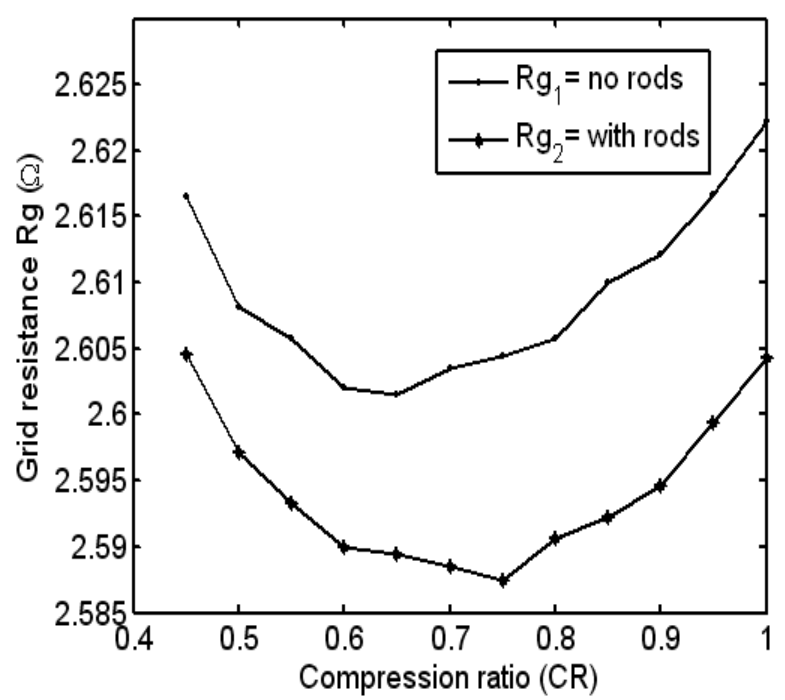

Fig -2: Impact of CR on grid resistance in uniform soil 


\section{TWO LAYER SOIL MODEL}

Two-layer soil model is represented by first layer with uniform soil of a finite depth and a second layer of uniform soil with infinite depth. The abrupt change in resistivity at the boundaries of each soil layer can be defined by means of a reflection factor. The reflection factor $\mathrm{K}$, is given by [14]

$$
K=\left(\rho_{2}-\rho_{1}\right) /\left(\rho_{2}+\rho_{1}\right)
$$

Where,

$\rho_{1}=$ resistivity of first layer upto certain finite depth.

$\rho_{2}=$ resistivity of second layer up to infinite depth

Two soil models used for the analysis are listed in table 2.

Impact of compression ratio on grid resistance for two layer soil model is similar to uniform soil model. However, it also depends on soil resistivity reflection factor $\mathrm{K}$, soil layer depth H. A square grid $100 \times 100 \mathrm{~m}$, with conductor spacing $\mathrm{D}=10 \mathrm{~m}, \rho_{1}=300 \Omega-\mathrm{m}, \rho_{2}=60 \Omega-\mathrm{m}$, grid current=10 KA , buried at a depth of 0.5m from IEEE Std 80-2000 annexure$\mathrm{E}$ is simulated using AGP software.

Table -2: Two layer soil models [15]

\begin{tabular}{|l|l|l|l|}
\hline Soil model & Layer & $\begin{array}{l}\text { Resistivity } \\
\Omega-\mathrm{m}\end{array}$ & $\begin{array}{l}\text { Thickness } \\
(\mathrm{m})\end{array}$ \\
\hline \multirow{3}{*}{$\mathrm{a}$} & First & 300 & 6.1 \\
\hline \multirow{3}{*}{$\mathrm{b}$} & Second & 60 & $\infty$ \\
\hline & First & 60 & 6.1 \\
\cline { 2 - 4 } & Second & 300 & $\infty$ \\
\hline
\end{tabular}

\subsection{Impact of CR on Grid Resistance}

The analyzed results for two layer soil model ' $a$ ' and soil model ' $b$ ' are listed in table 3.The effect of CR on grid resistance with soil resistivity reflection factor $\mathrm{K}<0$ and $\mathrm{K}$ $>0$ is as shown in fig.3 (a) and (b) respectively. For soil model ' $\mathrm{a}$ ', when $\mathrm{K}=-0.666$ i.e. when second layer resistivity is less as compared to first layer soil, the optimal compression ratio for grid resistance is 0.90 and grid resistance decreases from $0.4909 \Omega$ to $0.4890 \Omega$ where as for soil model ' $b$ ', $K=0.666$ i.e. when second layer resistivity is larger as compared to first layer, the optimal compression ratio for grid resistance becomes 0.40 and grid resistance changes from $0.8894 \Omega$ to $0.8794 \Omega$.Thus, for positive values of $\mathrm{K}$, the OCR is very small as compared to for soil model having same negative values of $\mathrm{K}$.

\subsection{Impact of $\mathrm{K}$ on Grid Resistance and OCR}

For two layer soil model, OCR is influenced by soil resistivity reflection factor,first layer depth $\mathrm{H}$ and area of grounding grid. OCR increases with decrease in values of $\mathrm{K}$ ,making grid more uniform. The effect of various values of $\mathrm{K}$ on OCR and grid resistance is listed in table 4 . We have analyzed the grid for various values of soil resistivity reflection factor $\mathrm{K}$ ranging from -0.80 to +0.80 . For $\mathrm{K}=0$ ie for uniform soil model grid resistance is maximum. Results reveal that for $\mathrm{K}<0$, yields the most efficient and economic grid resistance as compare to grid resistance for $\mathrm{K}>0$ as shown in fig.4 (a). As negative value of $\mathrm{K}$ increases, the grid current can be easily discharged into low resistivity second layer. For K >0, grid current cannot be discharged easily into ground because of high resistivity second layer resulting higher resistance as compared to negative values of K. Moreover, influence of first layer thickness $\mathrm{H}$ on grid resistance is depicted in fig.4 (b). As the thickness of first layer increases, the influence of first layer high resistivity becomes dominant which increases the optimal grid resistance.

Table -3: Impact of CR on grid resistance

\begin{tabular}{|l|l|l|}
\hline \multirow{2}{*}{$\mathrm{CR}$} & $\mathrm{K}=-0.666$ & $\mathrm{~K}=0.666$ \\
\cline { 2 - 3 } & $\mathrm{R}_{\mathrm{g}}(\Omega)$ & $\mathrm{R}_{\mathrm{g}}(\Omega)$ \\
\hline 1 & 0.4909 & 0.8894 \\
\hline 0.95 & 0.4899 & 0.8883 \\
\hline 0.90 & 0.4890 & 0.8872 \\
\hline 0.85 & 0.4916 & 0.8865 \\
\hline 0.80 & 0.4918 & 0.8853 \\
\hline 0.75 & 0.4925 & 0.8842 \\
\hline 0.70 & 0.4967 & 0.8834 \\
\hline 0.65 & 0.4990 & 0.8823 \\
\hline 0.60 & 0.5023 & 0.8813 \\
\hline 0.55 & 0.5070 & 0.8806 \\
\hline 0.50 & 0.5141 & 0.8800 \\
\hline 0.45 & 0.5206 & 0.8796 \\
\hline 0.40 & 0.5291 & 0.8794 \\
\hline 0.35 & 0.5428 & 0.8802 \\
\hline 0.30 & 0.5576 & 0.8814 \\
\hline 0.25 & 0.5757 & 0.8832 \\
\hline 0.20 & 0.5978 & 0.8859 \\
\hline
\end{tabular}

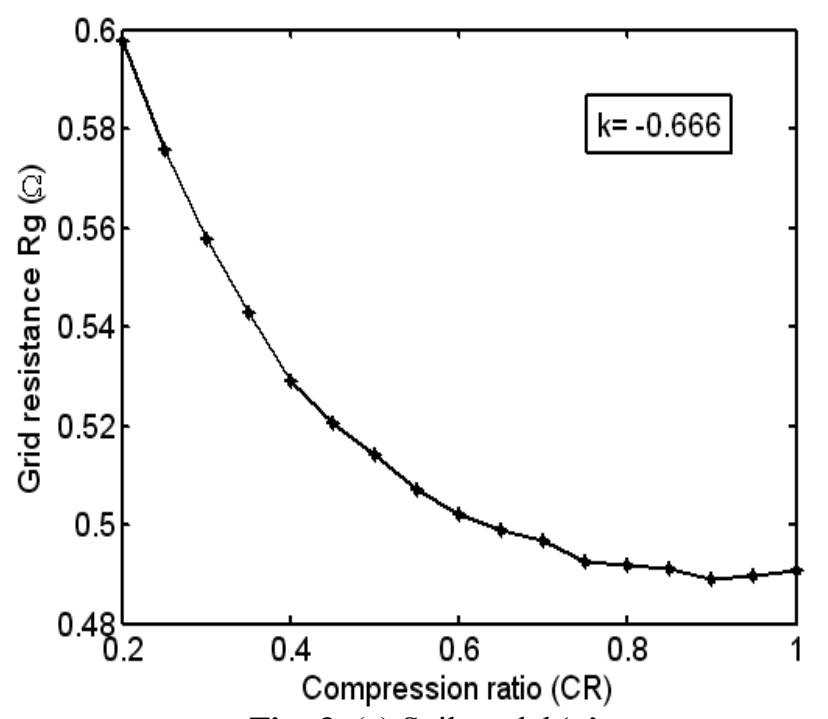

Fig -3: (a) Soil model 'a' 


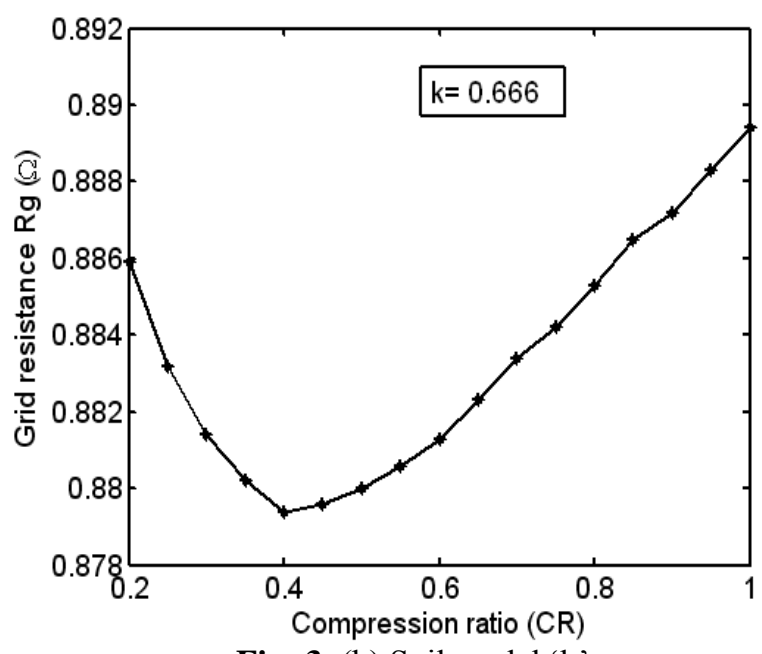

Fig -3: (b) Soil model 'b'

Table -4: Effect of K on OCR and $\mathrm{R}_{\mathrm{g}}$

\begin{tabular}{|l|l|l|}
\hline $\mathrm{K}$ & OCR & $\mathrm{Rg}$ \\
\hline-0.80 & 0.90 & 0.3803 \\
\hline-0.666 & 0.90 & 0.4890 \\
\hline-0.50 & 0.90 & 0.6472 \\
\hline-0.333 & 0.90 & 0.8372 \\
\hline 0.0 & 0.75 & 1.3625 \\
\hline 0.333 & 0.60 & 1.1370 \\
\hline 0.50 & 0.45 & 1.0222 \\
\hline 0.666 & 0.40 & 0.8791 \\
\hline 0.80 & 0.40 & 0.7165 \\
\hline
\end{tabular}

\section{MULTI LAYER SOIL MODEL}

For this study, we have selected four multilayer soil models as listed in table 5. The model 'c' having of low resistivity soil at second layer and high resistivity soil at the first and third layers. In soil model d, high resistivity soil layer is in between low resistivity layers. The soil model 'e', has high resistivity soil layer at the top and low resistivity layers in descending order where as in model ' $\mathrm{f}$ ' soil resistivities are in ascending order from top to bottom layer $[16,17]$.

The same grounding grid is used with and without ground rods. Fig. 5 and 6 shows the effect of CR on OCR and thereby on grid resistance for model $c, d$, e and $f$. The analysis shows that models ' $c$ ' and ' $\mathrm{f}$ ' behaves like two layer soil model ' $b$ ' with $\mathrm{K}<0$. Particularly soil model ' $c$ ' is somewhat similar to uniform soil model. This is because of equal high resistivity soil layers at first and third layer. The effect of CR on grid resistance for soil model d and 'e' is similar to two layer soil model ' $a$ '. The ground rods can be effectively used in these models, especially in model $\mathrm{d}$ and ' $\mathrm{e}$ ' because of low resistivity layers are in descending order[18]. Use of four rods at the four corner of the grid each of $5 \mathrm{~m}$ long decreases the grid resistance effectively. The analysis results for multilayer soil model are tabulated in table 6.

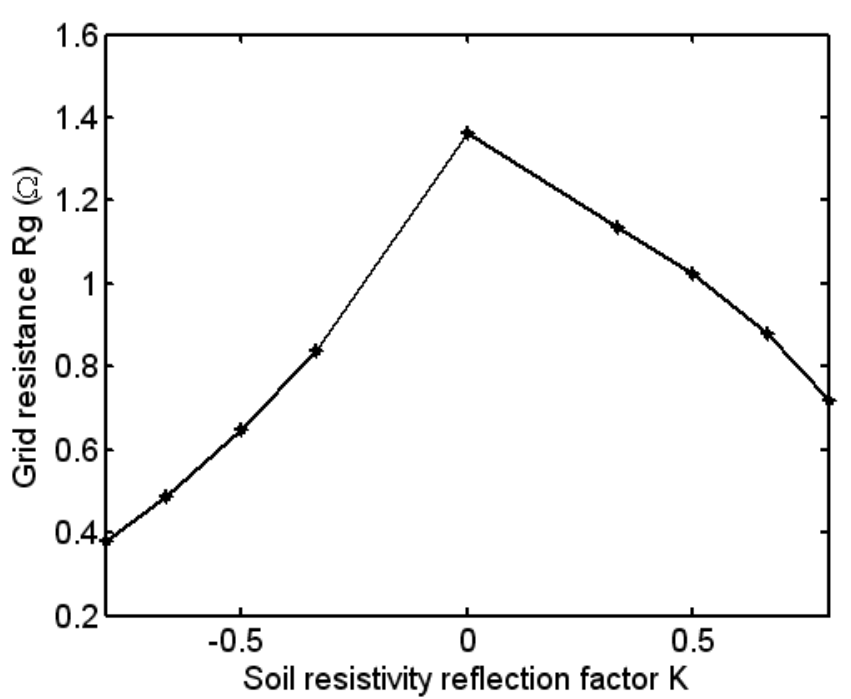

Fig -4: (a) Impact of $\mathrm{K}$

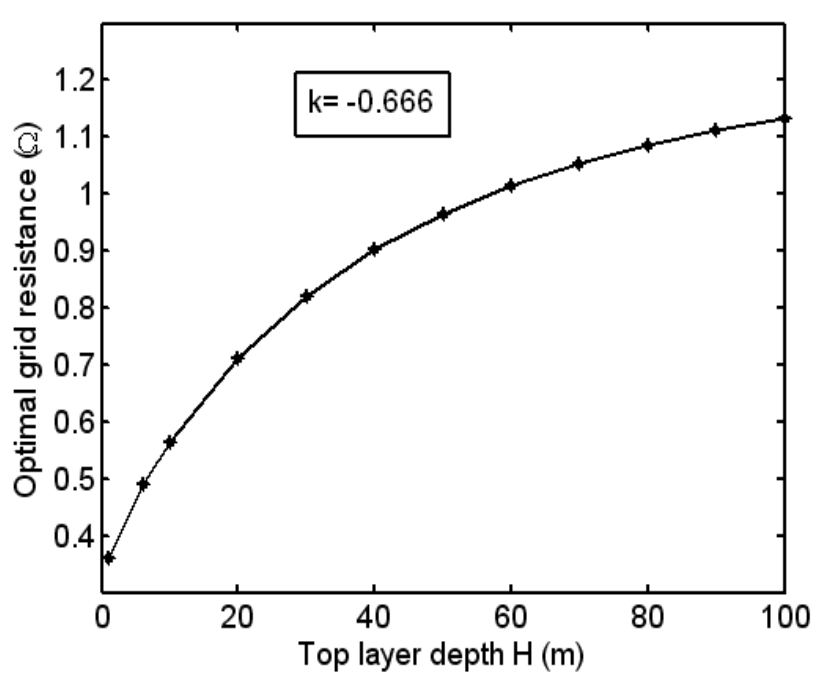

Fig -4: (b) Impact of top layer thickness $\mathrm{H}$

Table -5: Multilayer soil models [18]

\begin{tabular}{|l|l|l|l|}
\hline $\begin{array}{l}\text { Soil } \\
\text { model }\end{array}$ & Layer & $\begin{array}{l}\text { Resistivity } \\
(\Omega-\mathrm{m})\end{array}$ & $\begin{array}{l}\text { Layer } \\
\text { Thickness (m) }\end{array}$ \\
\hline \multirow{4}{*}{$\mathrm{c}$} & First & 300 & 3 \\
\cline { 2 - 4 } & Second & 60 & 3 \\
\cline { 2 - 4 } & Third & 300 & $\infty$ \\
\hline \multirow{4}{*}{$\mathrm{e}$} & First & 60 & 3 \\
\cline { 2 - 5 } & Second & 300 & 3 \\
\cline { 2 - 5 } & Third & 60 & 2 \\
\hline \multirow{5}{*}{$\mathrm{f}$} & First & 300 & 2 \\
\cline { 2 - 5 } & Second & 200 & 2 \\
\cline { 2 - 5 } & Third & 100 & 2 \\
\cline { 2 - 4 } & forth & 60 & 2 \\
\cline { 2 - 4 } & First & 60 & 2 \\
\cline { 2 - 4 } & Second & 100 & 2 \\
\cline { 2 - 4 } & Third & 200 & 2 \\
\cline { 2 - 4 } & forth & 300 & 2 \\
\hline
\end{tabular}



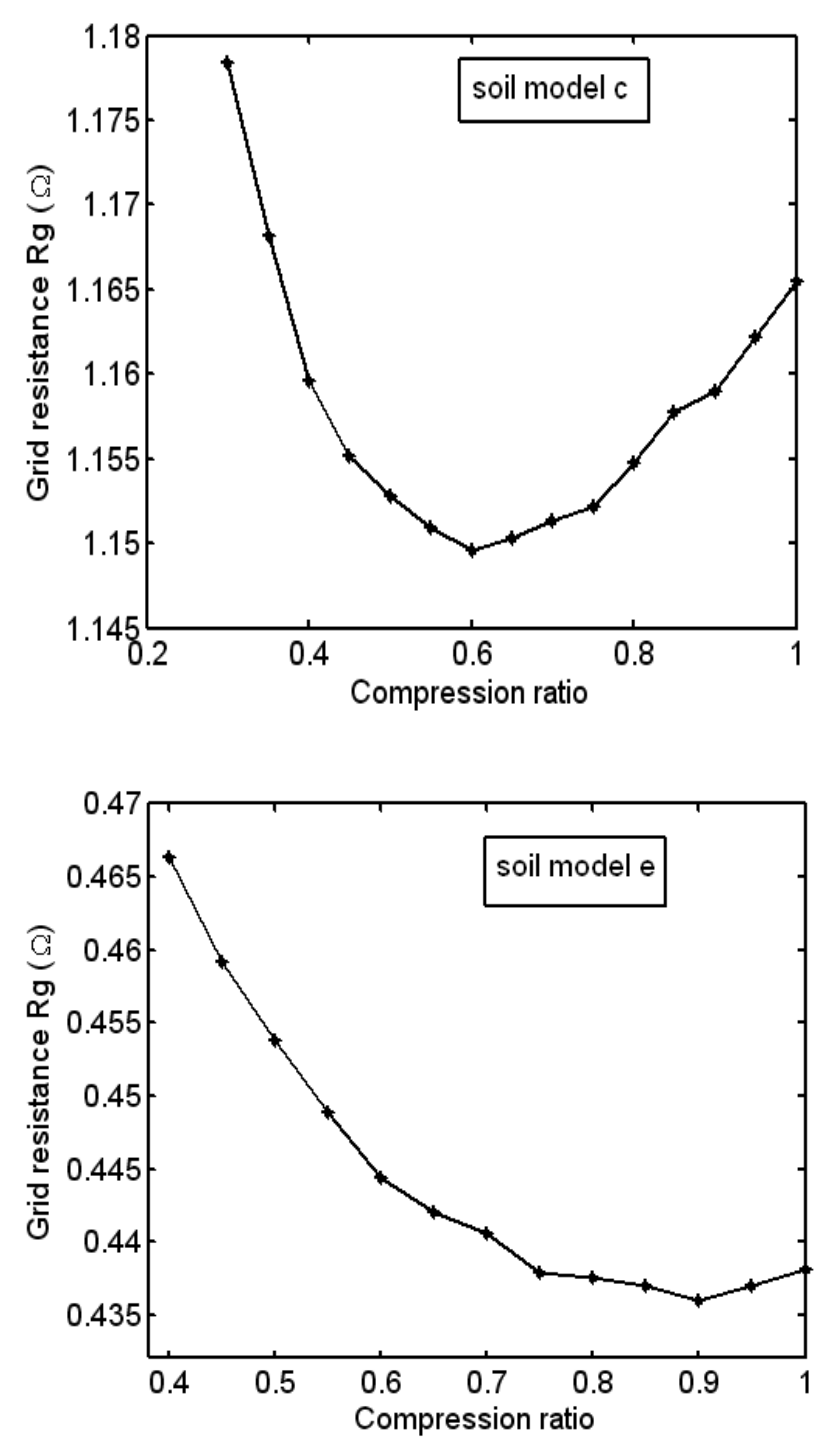

Fig -5: Impact of CR on grid resistance in multilayer soil models c, and e

Table -6: Results of multilayer soil models

\begin{tabular}{|l|l|l|l|}
\hline $\begin{array}{l}\text { Soil } \\
\text { model }\end{array}$ & Condition & OCR & $\begin{array}{l}\text { Grid } \\
\text { resistance }(\Omega)\end{array}$ \\
\hline $\mathrm{c}$ & no rods & 0.60 & 1.1496 \\
\cline { 2 - 4 } & with rods & 0.60 & 1.1293 \\
\hline $\mathrm{d}$ & no rods & 0.75 & 0.3260 \\
\cline { 2 - 4 } & with rods & 0.80 & 0.3247 \\
\hline $\mathrm{e}$ & no rods & 0.90 & 0.4360 \\
\cline { 2 - 4 } & with rods & 0.95 & 0.4296 \\
\hline $\mathrm{f}$ & no rods & 0.45 & 0.9887 \\
\cline { 2 - 4 } & with rods & 0.55 & 0.9725 \\
\hline
\end{tabular}
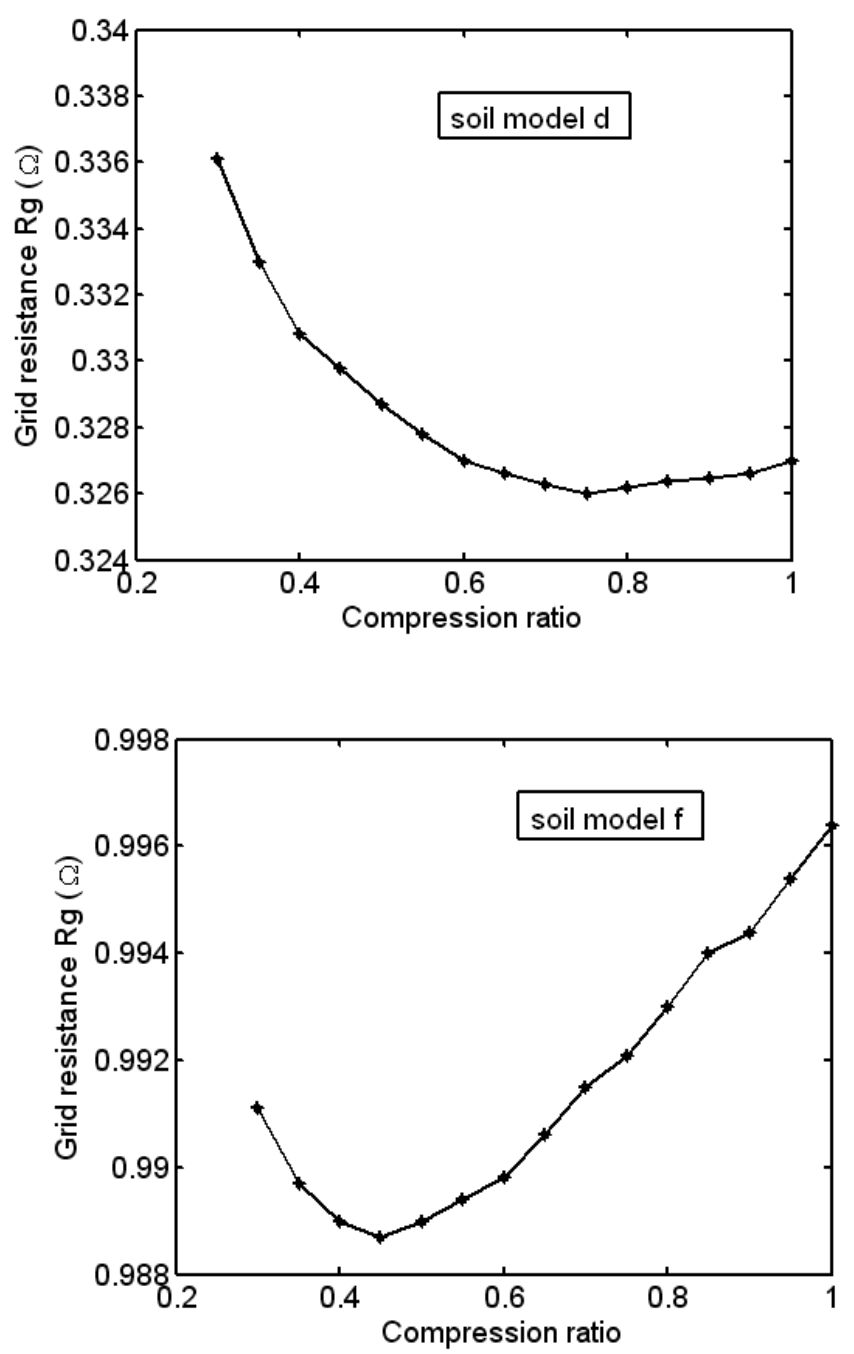

Fig -6: Impact of CR on grid resistance in multilayer soil models $\mathrm{d}$, and $\mathrm{f}$

\section{CONCLUSION}

The impact of grid compression ratio on grid resistance have been evaluated for various soil models like uniform, two layer and multilayer with and without ground rods. The study was carried out to obtain optimal compression ratio which will give minimum grounding grid resistance in order to have low GPR and thus the low value of transfer potential and enhance the safety. Further analysis is as given below.

- $\quad$ For uniform soil model, exponentially spaced grid with densely populated conductors at the periphery and rare at the central portion of the grid, results most economic and efficient design.

- In two layer soil model with $\mathrm{K}<0$, minimum value of grid resistance occurs at high value of CR making grid more uniform whereas for $\mathrm{K}>0$, minimum grid resistance yields at lower value of $\mathrm{CR}$ making the grid more non uniform.

- Ground rods increase the value of OCR and decrease the grid resistance. Ground rods are far more effective for soil structures having $\mathrm{K}<0$, especially when they penetrate into low resistivity soil layers. 
- In multilayer soil models 'c' and ' $\mathrm{f}$ ', the nature of grid resistance curves and OCR are similar to two layer soil model 'b'. Whereas, soil models' and 'e' behaves like soil model 'a'.

\section{REFERENCES}

[1] IEEE Std 80- 2000, IEEE Guide for Safety in AC Substation Grounding, IEEE, New York, USA.

[2] Unde, M.G. and Kushare, B.E., "Grounding grid performance of substation in two layer soil - a parametric analysis" ,International Journal of Engineering Sciences \& Emerging Technologies 1(2), pp. 69-76, Jan. 2012

[3] Laurent, P.G.," Les Base Generales da la Technique des Mise a la Terre dans les Installation Electriques," Bulletin de la Socite Francaise des Electriciens, Vol.1,ser.7 ,pp.368-402,July 1951

[4] Sverak,J.G.,"Simplified analysis of electrical gradients above a ground grid; Part I- How good is the present IEEE method?" IEEE Trans. on PAS vol. 103, No. 1, pp.7-25, Jan.1984

[5] IEEE Std 81-1983, IEEE Guide for Measuring Earth Resistivity, Ground Impedance, and Earth Surface Potentials of a Ground System, IEEE, New York, USA.

[6] Jinliang He, Rong Zeng, Bo Zang , “ Methodology \& technology for power system grounding”, John Wiley \& sons Singapore, 2013

[7] F. P. Dawalibi and D. Mukhedkar,"Parametric analysis of grounding grid", IEEE Trans. on PAS Vol.98 No. 5, pp. 1659-1668,Oct. 1979

[8] F. P. Dawalibi and D. Mukhedkar, " Optimum design of substation grounding in two layer earth structure",IEEE Trans. on PAS vol. 94, No. 2,Part II, pp. 262-266, April 1975

[9] F. P. Dawalibi and D. Mukhedkar, " Optimum design of substation grounding in two layer earth structure",IEEE Trans. on PAS vol. 94, No. 2, Part III, pp. 267-272, April 1975

[10] J.G. Sverak, "Optimized grounding grid design using variable spacing technique", IEEE Transactions on Power Apparatus and Systems, Vol. PAS-95, No. 1, pp. 362-374, Jan./Feb. 1976.

[11] L. Huang X. Chen, H. Yan, " Study of unequally spaced grounding Grids", IEEE Transactions on Power Delivery, Vol. 10, No. 2,pp 716-722, April 1995

[12] O. Gauda, G. Amar and H Ibrahim, "Earth surface potential and GPR of substation grounding", CIRED, pp 1-6, June 2011
[13] Earthing of A. C. Power Systems. 302, C.B.I.P., New Delhi, India, 2007

[14] IEEE Std 81-2012, IEEE Guide for Measuring Earth Resistivity, Ground Impedance, and Earth Surface Potentials of a Ground System, IEEE, New York, USA.

[15] Unde, M.G. and Kushare, B.E.," Effect of compression ratio on touch voltage in layered soil", in Proc. IEEE sixth Power India Conference, Dec.2014, In press.

[16] Unde, M.G. and Kushare, B.E., " Cost effective design of grounding grid using ground rods- a case study", in Proc. IEEE Fifth Power India Conference , pp. 1-6, Dec.2012.

[17] F P Dawalibi, J Ma, R D Southey, "Behavior of grounding system in multilayer soils: a parametric analysis", IEEE Trans. PWRD vol.9, No 1, pp.333342, Jan. 1994

[18] Unde, M. G. and Kushare, B.E., "Impact of seasonal variation of soil resistivity on safety of substation grounding system", in Proc. IET Conference, pp.173181, Sept.2013.

\section{BIOGRAPHIES}

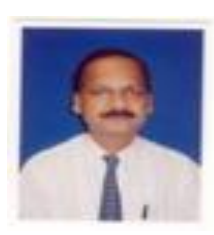

Prof. M.G. Unde is working as Professor in Electrical Engineering Deptt..at Pad. Dr. Vithalrao Vikhe Patil College of Engineering, Ahmednagar from last 27 years. He has completed his Graduate degree B.E. Elect. in 1986 from Government College of Engineering Pune and Masters Degree M.E. Power System in 1998 from the same College. Presently, he is doing Ph.D. under guidance of Dr. B.E. Kushare at K K W I E E \& R Nashik University of Pune. His research interest is, power system analysis and power system grounding design and analysis.

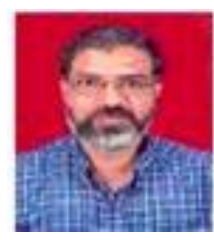

Prof. Dr. B. E. Kushare had completed his Ph.D. in Power Quality from Pune University. He is Prof. \& Head of Electrical Engineering in K. K. Wagh Institute of Engg. Edu \& Research, Nashik. He is a Ph.D. Guide of University of Pune. He has published about fifty research papers in various National ,International conferences and journals. He is certified energy auditor and power quality consultant. He is associated with various industries, National institutes and IITs 